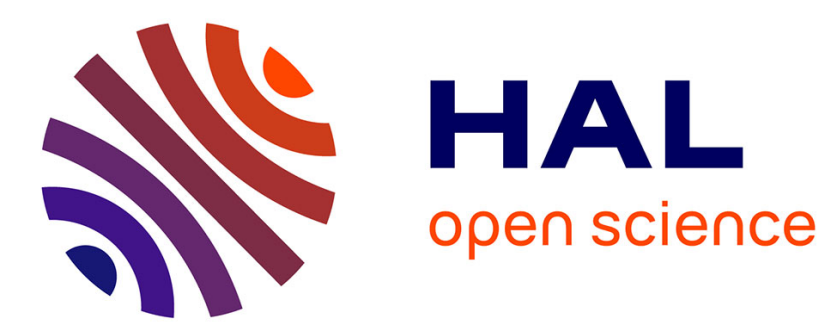

\title{
PULSED ELECTRON BEAM ANNEALING OF ARSENIC-IMPLANTATION DAMAGE IN SILICON
}

Damien Barbier, A. Laugier, A. Cachard

\section{To cite this version:}

Damien Barbier, A. Laugier, A. Cachard. PULSED ELECTRON BEAM ANNEALING OF ARSENIC-IMPLANTATION DAMAGE IN SILICON. Journal de Physique Colloques, 1982, 43 (C5), pp.C5-411-C5-420. 10.1051/jphyscol:1982547 . jpa-00222267

\section{HAL Id: jpa-00222267 https://hal.science/jpa-00222267}

Submitted on 1 Jan 1982

HAL is a multi-disciplinary open access archive for the deposit and dissemination of scientific research documents, whether they are published or not. The documents may come from teaching and research institutions in France or abroad, or from public or private research centers.
L'archive ouverte pluridisciplinaire HAL, est destinée au dépôt et à la diffusion de documents scientifiques de niveau recherche, publiés ou non, émanant des établissements d'enseignement et de recherche français ou étrangers, des laboratoires publics ou privés. 
JOURNAL DE PHYSIQUE

Colloque C5, supplément au n²12, Tome 43, décembre 1982

page $\mathrm{C5}-411$

PULSED ELECTRON BEAM ANNEALING OF ARSENIC-IMPLANTATION DAMAGE IN SILICON

\author{
D. Barbier, A. Laugier and A. Cachard* \\ Laboratoixe de Physique de la Matière (ERA 544), Institut National des \\ Sciences Appliquées de Lyon, 20, Avenue Albert Einstein, 69621 Villeurbanne \\ Cedex, Eronce \\ * Département de Physique des Matériaux, Université Claude Bermard, Lyon I, \\ 43, Boulevard du 11 Novembre 1918, 69628 Villeurbanne Cedex, France
}

\title{
RESUME
}

Un canon à faisceau d'électrons pulsé SPIRE-300 a été utilisé pour recristalliser des couches de Si (100) et (111) implanté avec As $\left(140 \mathrm{keV}-10^{15} \mathrm{~cm}^{-2}\right)$. Les paramètres de la machine ont été choi sis pour obtenir un profil de dépót d'énergie des électrons adapté à la fusion superf icielle du silicium à partir de $1 \mathrm{~J} / \mathrm{cm}^{2}$.

La qualité cristalline, ainsi que l'incorporation de l'arsenic atteignent un maximum dans la gamme de densité superficielle d'énergie : $1,2-1,4 \mathrm{~J} / \mathrm{cm}^{2}$. Aucun ef fet important d'orientation n'a été mis en évidence mais une limite supérieure de dégradation à environ $1,6 \mathrm{~J} / \mathrm{cm}^{2}$ a été clair ement observée pour les deux orientations. Létalement du profil d'arsenic est cohérent avec le modèle de fusion. Cependant, des pertes importantes d'arsenic, pendant la durée de la phase liquide pour raient être responsables de la chute de concentration observée expérimentalement à la surface par rapport aux résultats obtenus par le calcul au moyen d'un modèle simple de diffusion.

\section{ABSTRACT}

A SPIRE-300 pulsed electron beam processor has been used to recrystallize (100) and (111) Si wafers implanted with As $\left(140 \mathrm{keV}-10^{15} \mathrm{~cm}^{-2}\right)$. The machine parameters have been selected to obtain an electron energy deposition prof ile convenient for melting of the silicon surface down to $1 \mathrm{~J} / \mathrm{cm}^{2}$.

The best r egr ow th layer quality and As incorporation were obtained with electron energy densities in the range $1.2-1.4 \mathrm{~J} / \mathrm{cm}^{2}$. No signi ficant orientation ef fects have been detected but a degradation upper limit of about $1.6 \mathrm{~J} / \mathrm{cm}^{2}$ was clearly observed for both orientations. Spreading of the As prof ile was consistent with the melting model. However, significant As losses during the melt stage might be responsible for the drop in the surface concentrations experimentally measured compared to results of a simple diffusion model.

\section{INTRODUCTION}

Ion implantation folbwed by a single submicrosecond high energy pulse is now considered as a very at tractive doping process either for the microelectronic or for the solar cels industry. In addition to its main advantages over classical diffusion (better control of doping profiles, low impurity contamination, no modification in bulk peoperties) it albws high throughputs and bw production costs (1)(2). Since a few years it has been demonstrated that short duration ( $<100 \mathrm{~ns}$ ) pulsed laser or electron beams can be used to remove implantation damage in silicon by liquid phase epitaxial regr ow th from the undamaged subs trate (3) (4). Thermal ef fects such as maximum molten layer thickness, liquid phase duration and melt front velocity are determined by both the beam energy deposition pr of ile and the incident energy density (fluence). In the case of electrons these parameters can be largely modified by variation of acceleration voltages and beam currents. 
In this work Pulsed Elect ron Beam Annealing (PEBA) has been used to recrys tallize p-type (100) and (111) silicon implanted with As in concentration lower than the equilibrium limit solubility. Parameters of the pulsed electron beam processor have been selected to obtain an electron energy deposition prof ile convenient for surface melting of silicon. Excellent regr ow th layer quality and As incorporation in lat tice sites have been obtained in the fluence range $1.2-1.4 \mathrm{~J} / \mathrm{cm}^{2}$.

Computer simulation of the PEBA induced thermal ef fects and experimental results are presented. Importance of optimizing PEBA parameters to obtain the best regrow th layer quality and the highest As substitutionality is emphasized.

\section{ELECTRON BEAM PARAMETERS AND INDUCED THERMAL PROCESSES}

A schematic diagr am of the SPI-300 pulsed electron beam processor used for annealing is shown on $\mathrm{fig} .1$.

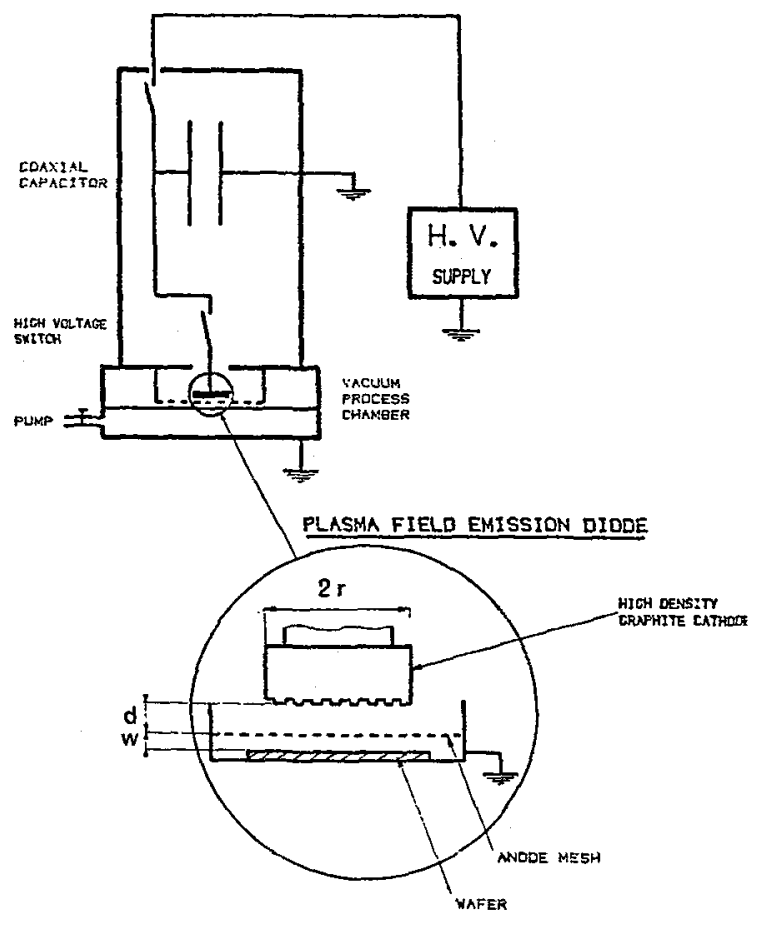

Figure 1 - Schematic diagram of the SPIRE-300 pulsed electron beam processor

This machine consists in a coaxial capacitive energy store $(3 \mathrm{nF})$ that is charged to a high voltage $(50-100 \mathrm{kV})$ with a high voltage supply. The electron beam pulse is obtained by discharge of the capacitor in a vacuum plasma field emission diode. The cathode is made of high density gr aphite and a tungsten mesh is used as anode to improve beam uniformity on the target. The process chamber pressure is main tained below $10^{-5}$ Torr to minimize plasma formation from residual gases. The capacitor maximum energy of $15 \mathrm{~J}$ allows to use cathode radii $\mathrm{r}$ up to $14 \mathrm{~mm}$ for a $1 \mathrm{~J} / \mathrm{cm}^{2}$ beam fluence. With cathode-anode gaps $\mathrm{d}$ in the range $1-2 \mathrm{~mm}$ most of the capacitor energy can be extracted from the diode with a pulse duration slightly varying around $50 \mathrm{~ns}$. Electron beam energy distribution of the pulse depends mainly on impedance matching between the plasma field, emission diode and the coaxial capacitor line. Diode 
impedance can be varied by modification of the $r / d$ ratio. For various diode geometries timeresolved spectroscopy of the electron beam pulse have been achieved by mean of analysis of diode cur rent and voltage waveforms. Monte-Carlo calculation of normalized time-integrated energy deposition pr of iles in silicon are shown on fig. 2 as a function of 3 values of the $\mathrm{r} / \mathrm{d}$ ratio.

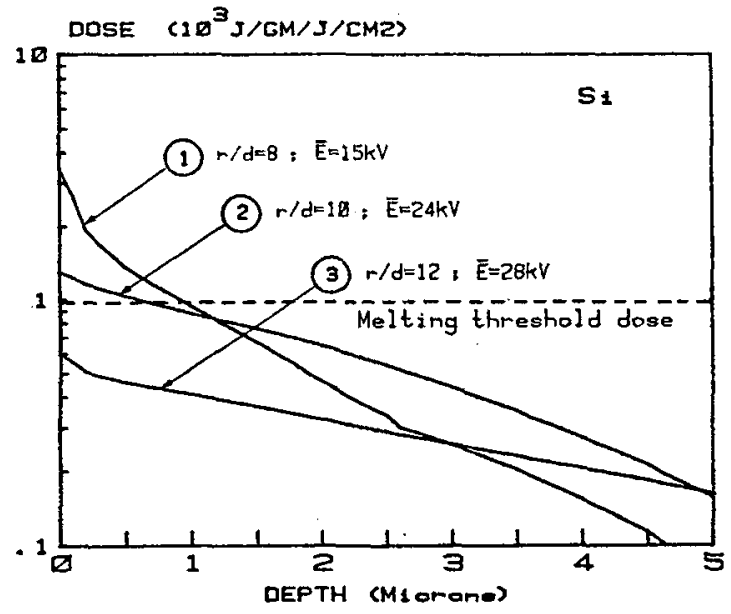

Figure 2 - Monte-Carlo calculation of normalized time-in tegr ated electron energy deposition prof iles in silicon as a function of different plasma field emission diode geometries.

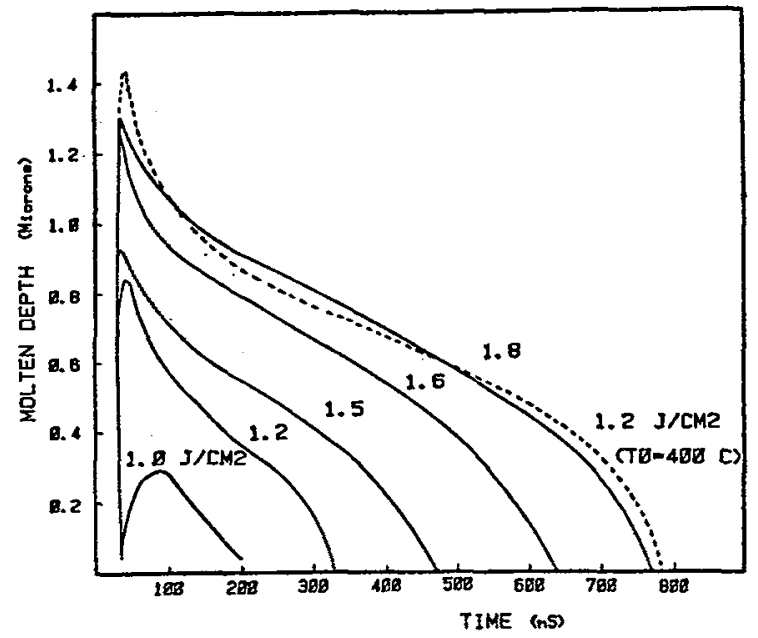

Figure 3 - Calculated melt-front motion curves versus fluence for depth-dose curve $n^{\circ} 1$ of fig. 2 


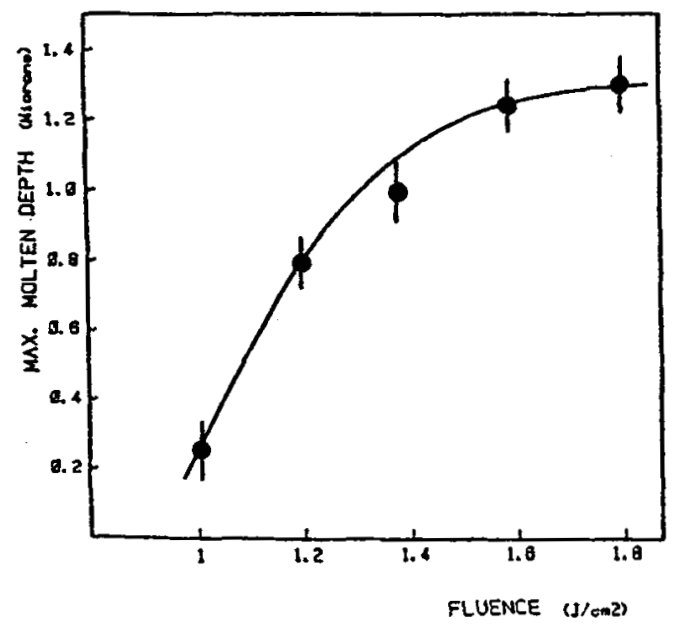

Figure 4 - Maximum molten layer thickness versus fluence

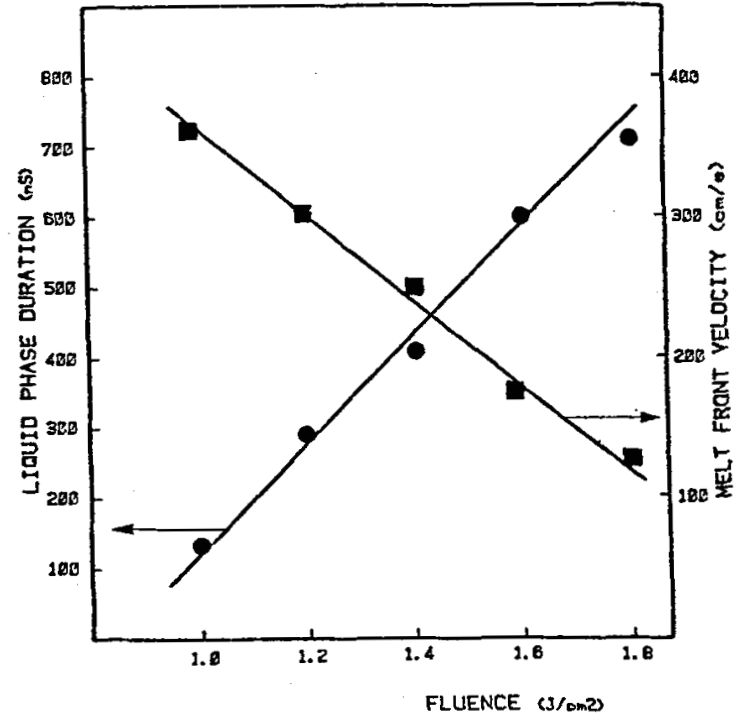

Figure 5 - Liquid phase duration and melt-front velocity versus fluence. 
Assuming no signi ficant heat diffus ion during irradiation the depth-temperature curves after pulse are roughly proportional to the depth-dose curves. So only diode geometry $n^{\circ} 1$ will be convenient for superf icial transient liquid phase epitaxy with a beam fluence of the order of $1 \mathrm{~J} / \mathrm{cm}^{2}$. Thermal ef fects of the pulses have been determined with diode geometry $n^{\circ} 1$ for various beam fluences by numerical solution of the one-dimensional heat $f$ low equation. Fluence has been varied by adjusting the capacitor charging voltage by less than $30 \%$ around a nominal value taking care to keep the normalized electron depth-dose profile nearly unchanged. Fluence measurement has been carried out by mean of a graphite calorimeter with an accuracy of $\pm 6 \%$. The melting model accounts for latentheat by assuming a singularity in the specific heat curve at the melt temperature. A $0.2 \mu$ thick amorphous layer with latent heat $40 \%$ lower than the crystal value has been as sumed (5). Fig. 3 shows the calculated melt front motion curves as a function of the beam fluence. The starting silicon temperature was $20^{\circ} \mathrm{C}$ except for one case for which we have simulated the ef fect of heating the specimen up to $400^{\circ} \mathrm{C}$ before pulsing. $A$ few tenth of microns are molten within the pulse duration and the liquid-solid in terface retre ts back to the surface with a fluence-dependent velocity. Analysis of temperature pr of iles have shown that thermal gradients during irradiation have a maximum value varying from 400 to $600^{\circ} \mathrm{K} / \mu \mathrm{m}$ when fluence is raised from 1 to $1.6 \mathrm{~J} / \mathrm{cm}^{2}$. During solidification, quenching $\mathrm{r}$ ate is about $10^{\circ} \mathrm{C} / \mathrm{s}$. Fig.4 shows that the maximum molten layer thickness is about $0.25 \mu$ with $1 \mathrm{~J} / \mathrm{cm}^{2}$. It raises rapidly up to $0.8 \mu$ with only $1.2 \mathrm{~J} / \mathrm{cm}^{2}$ and fol lows a logarithmic-like law. This behaviour is a consequence of the quasi logarithmic variation of the electron depth-dose curve (see fig.2). So, with the selected electron beam pulse fluence can be adjus ted to melt the silicon surface beyond the amorphous zone produced by a shallow implantation. In the other hand the liquid phase duration increases quasi linearly with fluence as shown on $f$ ig.5. On the same figure is plotted the corresponding mean liquid-solid interface velocity which is a decreasing function of fluence in the range $1-4 \mathrm{~m} / \mathrm{s}$. Both curves can be explained by the depth-limited energy deposition prof ile and molten zone which causes more heat to be absorbed in the melt when fluence is increased. It therefore requires a longer time to be evacuated in the solid.

The same angument can be used to explain, the shape of the melt-ffont motion curve calculated with a sample temperature of $400^{\circ} \mathrm{C}$ before pulsing with only $1.2 \mathrm{~J} / \mathrm{cm}^{2}$ (doted line on Fig. 3). This curve exhibits approximately the same features as the one calculated with a beam fluence of $1.8 \mathrm{~J} / \mathrm{cm}^{2}$ and a $20^{\circ} \mathrm{C}$ starting temperature. In fact, a lower energy density is conter-balanced by a $30 \%$ decr ease of the heat needed to reach the melt temperature when the specimen is heated up to $400^{\circ} \mathrm{C}$ before pulsing. Consequently, more heat is absorbed in the melt. Moreover thermal gradients beneath the molten zone are reduced so that a longer time is required to evacuate the latent heat from the melt. This results in a longer phase duration and a lower mean melt front velocity than in the case of a $20^{\circ} \mathrm{C}$ starting temperature.

\section{EXPERIMENTAL RESULTS}

The p-type CZ (100) and (111) silicon wafers were implanted with $10^{15}$ ions $/ \mathrm{cm}^{2}$ of arsenic at $140 \mathrm{keV}$. After implantation they were annealed starting from $20^{\circ} \mathrm{C}$ with the previously described electron beam pulse in the fluence range $1-1.6 \mathrm{~J} / \mathrm{cm}^{2}$. Crystal quality and dopant redistribution has been inves tigated by mean of RBS measurements in the random and aligned direction.

Fig.6 shows $2 \mathrm{MeV}^{4} \mathrm{He}^{+}$RBS spectra obtained on (100) Si before and after PEBA. The As implantation produces a $200 \mathrm{~nm}$ thick amorphous layer and the dopants distribution has a gaussian shape as shown on the aligned spectrum $n^{\circ} 2$. With $1 \mathrm{~J} / \mathrm{cm}^{2}$ (spectrum $n^{\circ} 3$ ) the implantation damages are only partially removed and the As substitutionality is below $70 \%$. Between 1.2 and $1.4 \mathrm{~J} / \mathrm{cm}^{2}$ (spectrum $\mathrm{n}^{\circ} 4$ ) the Si residual disorder drops down to $4 \%$ and the fraction of substitutional As is in the range 90-100\%. When the fluence is raised up to $1.6 \mathrm{~J} / \mathrm{cm}^{2}$ (spectrum $\mathrm{n}^{\circ}$ ) a dichanneling is clearly observed starting at about $300 \mathrm{~nm}$ from the surface. Although the Si residual disorder measured in the previously amorphous zone remains below $5 \%$. This sugges ts that crystal defects are induced by PEBA at high fluences beyond the amorphous zone. The dichanneling is increased when the same wafer undergoes 2 and 4 over- 
lapping shots at $16 \mathrm{~J} / \mathrm{cm}^{2}$. Moreover the Si residual disorder is increased with 4 overlapping shots as can be seen on Fig.7.

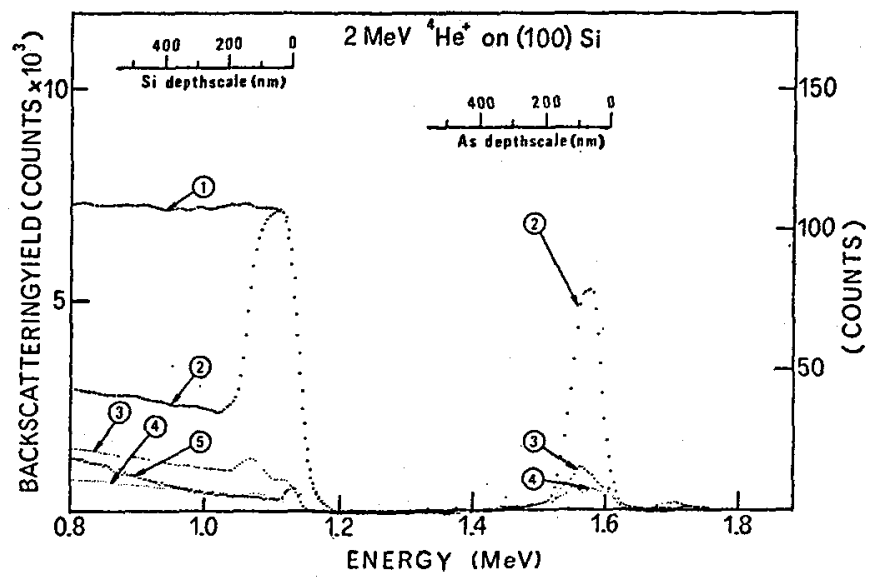

Figure 6 - RBS spectra of (100) Si implanted with $10^{15} \mathrm{As} / \mathrm{cm}^{2}$ at $140 \mathrm{KeV}$ in the random direction (1); aligned not annealed (2); aligned after PEBA with $1 \mathrm{~J} / \mathrm{cm}^{2}$ (3) ; aligned after PEBA with 1.2 to $1.4 \mathrm{~J} / \mathrm{cm}^{2}(4)$; aligned after PEBA with $1.6 \mathrm{~J} / \mathrm{cm}^{2}$ (5).

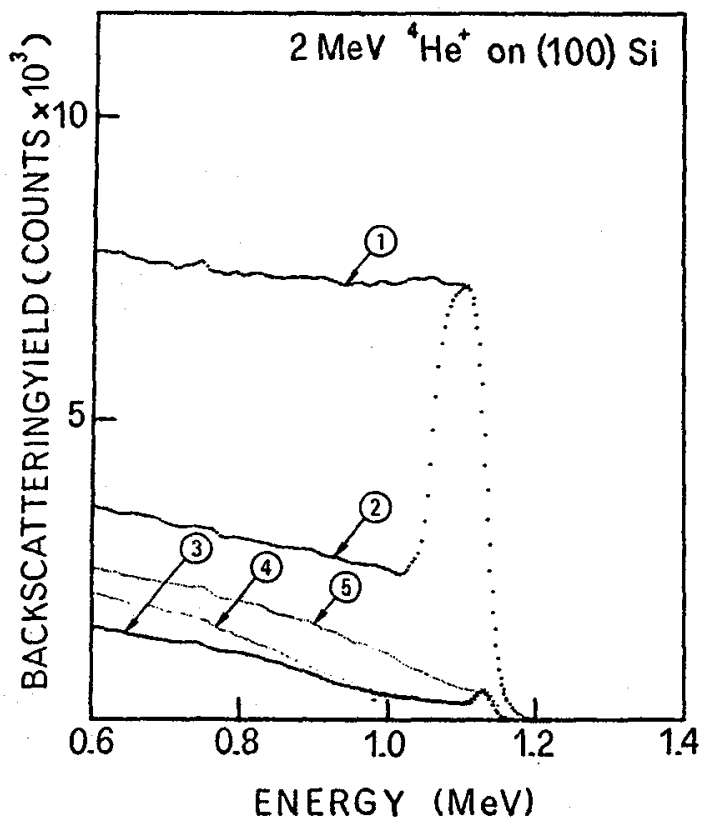

Figure 7 - RBS spectra of (100) Si implanted with $10^{15} \mathrm{As} / \mathrm{cm}^{2}$ at $140 \mathrm{KeV}$ in the random dir ection (1) aligned not annealed (2) and after PEBA at $1.6 \mathrm{~J} / \mathrm{cm}^{2}$ : one shot (3), two shots (4), four shots (5). 
For (111) Si nearly the same features are observed but the Si residual disorder is slightly lower than for (100) Si. Fig. 8 exhibits for both orientation a $1 \mathrm{~J} / \mathrm{cm}^{2}$ fluence threshold for good reordering of the silicon layer and high incorporation of As atoms in lat tice sites. It can be seen that the fraction of substitutional As is also slightly lower for (100) Si than for (111) Si but the differences are of the order of the RBS noise amplitude. Moreover for both orientations PEBA at $1.6 \mathrm{~J} / \mathrm{cm}^{2}$ results in a poor As substitutionality. After two overlapping shots at the same fluence the fraction of substitutional As remains unchanged and after 4 overlapping shots it decreases in the same time that we observe an increase of the disorder in the surface layer (see fig.7).

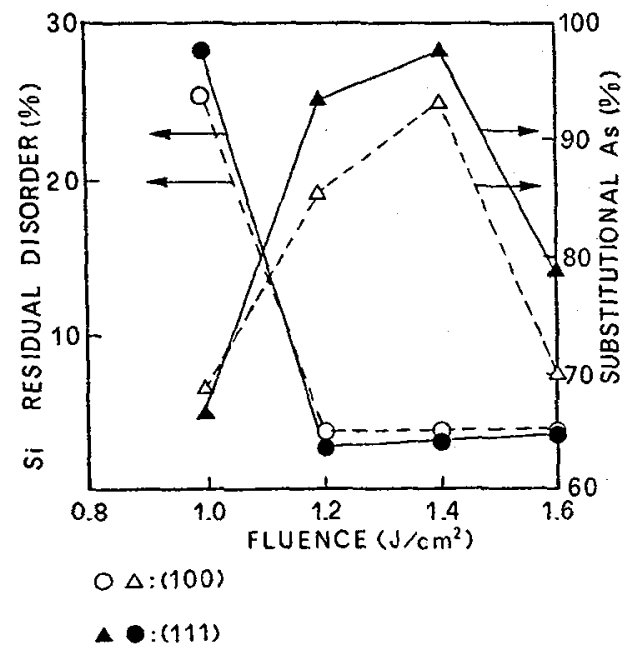

Figure 8 - Evolution of the Si residual disorder and As substitutionality after PEBA as a function of fluence.

Dopants redistribution has been analysed by RBS measurements in the random direction on PEBA Si wafers for several beam fluences. Fig.9 shows the spreading of the As implantation prof ile in (100) Si after PEBA with $1.4 \mathrm{~J} / \mathrm{cm}^{2}$ and $1.6 \mathrm{~J} / \mathrm{cm}^{2}$. Starting from the melt-front motion curves of $\mathrm{Fig} \cdot 3$ dopants $r$ edistribution have been numerically calculated using a simple diffusion model in which segregation ef fects are neglected (6).

The implantation prof ile has been divided into slices of equal thickness. For each slice of nearly constant concentration the As atoms were allowed to diffuse in the melt according to a gaussian law with a constant diffusivity. As the moving melt front sweeps the spreading prof ile the As concentration at the interface inside the liquid was assumed to be frozen in the underlying solid. At the surface the diffused profile was assumed to be reflected inward the material when no As losses were taken in to account. However it has been possible to assume that a percentage of As atoms reaching the surface could diffuse out of the material by partly reducing the ref lecting contribution at the surface. Finally, the resulting As profile was calculated by summing up the contributions of each initial profile slice. First As diffusivity has been adjus ted in order to $f$ it the experimental data. Good matching is obtained for the tail of the profiles with a diffusivity of $8 \times 10^{-5} \mathrm{~cm}^{2} / \mathrm{s} \pm 10 \%$. A more accurate determination was not possible in this work because of the noise amplitude in the RBS spectra. The value obtained is nevertheless in the range of the As diffusivity in liquid silicon (6). However, in the surface region a drop in As concentration is experimentally observed compared to the simulation. A good $f$ it of the near surface part of the profiles was possible only by assuming As losses during the melting phase. The computed curves are drawn on Fig. 9 in solid line and the calculated percentage of As losses increases linearly from $6 \%$ to $18 \%$ when fluence varies from 
1 to $1.6 \mathrm{~J} / \mathrm{cm}^{2}$. RBS measurements were also carried out on (111) Si wafer before and after PEBA, no significant orientation ef fect has been detected within the accuracy of the RBS measurements.

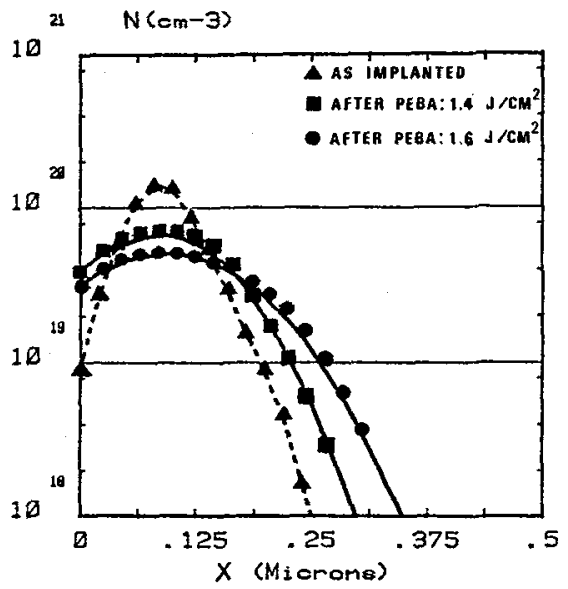

Figure 9 - RBS measurement of As pr of iles in (100) silicon as implanted $\left(140 \mathrm{KeV}-10^{15} / \mathrm{cm}^{-2}\right.$ and after PEBA $\left(1.2\right.$ and $\left.1.4 \mathrm{~J} / \mathrm{cm}^{2}\right)$.

\section{DISCUSSION}

The regrowth mechanism of an amorphous implanted layer submitted to pulsed annealing has been previously described by several authors (8)(9)(10). In particular the fluence threshold for single crystal regr ow th by liquid phase epitaxy depends on the depth of the induced molten layer compared to the amorphous layer thickness. Single crys tal regrow th is possible only if liquid-phase epitaxy is initiated beyond the damaged region in the single crys tal substrate. The relative simplicity to calculate the electron energy depth-dose in the specimen makes the comparison between experiments and thermal model less hazardeous in the case of electron beams as in the case of laser beams. Thus one can remark that the $1 \mathrm{~J} / \mathrm{cm}^{2}$ fluence threshold for good reordering of the implanted layer is consistent with the calculated molten layer thickness which exceeds the damaged layer only when fluence reaches $1 \mathrm{~J} / \mathrm{cm}^{2}$ whatever the substrate orientation.

Incorporation and redistribution of implanted impurities in Si by pulsed annealing has been studied mostly in the case of laser annealing with various dopant species and implantation parameters (11)(12). In this work the selected implantation parameters lead to a maximum As concentration below the equilibrium limit solubility. So the fraction of As in substitutional site after PEBA is mainly related to the crystal quality of the regrowth layer which depends on the thermal process induced in the specimen. For fluences up to $1 \mathrm{~J} / \mathrm{cm}^{2}$ the threshold for lat tice recovery is not exceeded and a high fraction of As in substitutional site cannot be obtained. Between 1.2 and $1.4 \mathrm{~J} / \mathrm{cm}^{2}$ the remaining As interstitial fraction is buried into the noise of the RBS spectrum for (111) Si but it is still detectable for (100) Si. This weak orientation ef fect might be related to the lower Si residual disorder measured in (111) samples compared to $(100)$ samples. Although fur ther experiments will be necessary to precise this point it is likely that liquid phase epitaxial regrow th with high melt front velocities will result in crys talline plane rearrangement and As incorporation depending on the substrate orientation. Moreover, in our experiments, the melt front velocity is a fluence dependent parameter (see Fig.5) so that even when melting occurs beyond the amorphous layer the resulting As substitutionality can be modified as a function of fluence above the threshold As it was pointed out by Kimerling et al. (13) at high in terface velocities non equilibrium point defects may 
be trapped due to their relatively low mobility in the solid state. This might explain why the As in terstitial fraction observed with $1.2 \mathrm{~J} / \mathrm{cm}^{2}$ is slightly higher than with $1.4 \mathrm{~J} / \mathrm{cm}^{2}$ because for this fluence the melt front velocity is $17 \%$ lower than with $1.2 \mathrm{~J} / \mathrm{cm}^{2}$. Moreover, the drop in As substitutionality with $1.6 \mathrm{~J} / \mathrm{cm}^{2}$ although the melt front velocity is only $1.6 \mathrm{~m} / \mathrm{s}$ is likely to be due to in troduction of defects beneath the molten layer when high thermal gradients $\left(\approx 600^{\circ} \mathrm{C} / \mathrm{\mu m}\right)$ are applied to the specimen during ir radiation. The fact that several overlapping shots with the same fluence produce an increase of the defects density (see RBS spectra of Fig.7) is an evidence for defects creation deeper than the molten depth produced by a $1.6 \mathrm{~J} / \mathrm{cm}^{2}$ shot. This explains why they cannot be annealed by a subsequent shot. The results and discussion about As incorporation in lat tice sites are supported by recent As electrical activity measur ements versus fluence which exhibit a peak value for a $1.4 \mathrm{~J} / \mathrm{cm}^{2}$ shot. Finaly it seems that the best $r$ esults are obtained with the fol bwing PEBA conditions : fluence must be sufficiently high to produce melting beyond the amorphous zone but thermal gradients during ir radiation and melt-front velocities must not exceed threshold values. This could be achieved by pulsing wafers previously heated above the ambient temperature asshown by the computer calculation of section Il. Experiments supporting this idea should be shortly carried out. Concerning As redistribution the PEBA induced prof iles are well fitted with a simple diffusion model. The deduced As diffusivity in liquid silicon $\left(8 \times 10^{-5} \mathrm{~cm}^{2} / \mathrm{s}\right)$ is lower than the lit terature values obtained from laser annealing experiments $\left(3 \times 10^{-4} \mathrm{~cm}^{2} / \mathrm{s}\right)(14)$. The absence of orientation ef fect in As redistribution is not a surprising features. Indeed segr egation which is a major orientation dependent phenomenon in dopants redistribution during fast regr ow th do not play any significant role in the case of As because its equilibrium segr egation coefficient is 0.3 and reaches unity during fast resolidification as shown in laser annealing experiments $(7)$.

Moreover the drop in As concentrations observed at the surface is probably due to As losses during the liquid phase. Indeed even with As concentrations in the range $10^{19}-10^{20} \mathrm{~cm}^{-3}$ the As partial pressure over liquid silicon is very high. The sample being processed in a vacuum of about $10^{-6}$ Torr it is likely that even a liquid phase duration of a few hundred of nanoseconds is sufficient to produce As diffusion out of the material. This hypothesis is supported by the fact that the calculated As losses are increased linearly with fluence in the same proportion as the liquid phase duration.

\section{CONCLUSION}

In this work a puised electron beam has been used to recrys tallise (100) and (111) silicon wafers implanted with As $\left(140 \mathrm{keV}, 10^{15} \mathrm{~cm}^{-2}\right)$. The experimentally determined fluence threshold $\left(1 \mathrm{~J} / \mathrm{cm}^{2}\right)$ for lattice recovery is consistent with a computer calculation of the molten depth which is of the order of the amorphous layer thickness for this fluence. The best results are obtained with the $1.4 \mathrm{~J} / \mathrm{cm}^{2}$ shot for which the Si residual disorder is below $5 \%$ and the fraction of substitutional As in the range 90-100\% for both orientations. Moreover, a degradation of the crystal below the amorphous layer is observed when fluence is raised up to $1.6 \mathrm{~J} / \mathrm{cm}^{2}$. Defects creation beneath the molten layer is evidenced by the increase of the defect density when the same sample undergoes 2 or 4 overlapping shots at $1.6 \mathrm{~J} / \mathrm{cm}^{2}$. Dopant redistribution is consistent with the melting model although the deduced As diffusivity is lower than the values reported in laser annealing experiments. A drop of the As surface concentration that cannot be $f$ itted by a simple diffusion model might be due to As losses during the melting process.

\section{REFERENCES}

(1) LANDIS G.A., ARMINI A.J., GREENWALD A.C., KIESLING R.A., 15 th IEEE Photovoltaic Specialists Conf. (1981) 976

(2) KATZEFF J.S., LOPEZ M., BURGER D.R., 15th IEEE Photovoltaic Specialists Conf. (1981) 437 
(3) WHITE C.W., NARAYAN J., YOUNG R.T., MRS Prœeed.AIP 50 New York (1979) 275

(4) GREENWALD A.C., KIRKPATRICK A.R., LITTLE R.G., MINNUCCI J.A., J.Appl.Phys. 50,2 (1979) 783

(5) BAERI P., FOTI G., POATE J.M., CULLIS A.G., Phys.Rev.Lett. 45, 25 (1980) 2036

(6) RIMINI E., BAERI P., CAMPISANO S. U, FOTI G., MRS Proceed. AIP 50, New York (1979) 259

(7) WHITE C.W., wILSON S.R., APPLETON B.R., NARAYAN J., MRS Proceed. Academic Press (1980) 111

(8) HOONHOUT D., SARIS F., MRS Proceed. North-Holland, New York (1981) 31

(9) LIETOILA A., GIBBONS J., MRS Proceed. North-Holland, New York (1981) 23

(10) BAERI P., FOTI G., POATE J.M., CULLIS A.G., MRS Proceed. North-Holland, New York (1981) 39

(11) HOONHOUT D., SARIS F.W., MRS Proceed. Academic Press (1980) 137

(12) WHITE C.W., APPLETON B.R., STRITZKER B., ZEHNER D.M., WILSON S.R., MRS Proceed. North-Hol land, New York (1981) 59

(13) KIMERLING L.C., BENTON J.L., MRS Proceed. Academic Press (1980) 385

(14) WHITE C.W., WILSON S.R., APPLETON B.R., YOUNG Jr F.W., J.Appl.Phys. 51(1980) 738

(15) KODERA H., Jap.J.Appl.Phys. 2 (1963) 212. 